\title{
Ham Petrol Fiyatları ve Katılım Endeksleri Arasındaki İlişkinin Tespitine Yönelik Bir Araştırma ${ }^{1}$
}

\section{A Research On Determination of The Relationship Between Crude Oil Prices and Participation Indices}

\author{
Yaşar ALPTÜRK * \\ Mert Baran TUNÇEL ** \\ Tayfun YILMAZ ${ }^{* * * *}$ \\ $\dot{I}_{\text {Ssmail } B E K C \dot{I}^{* * * * *}}$
}

\section{$\ddot{O} Z$}

Küreselleşmeyle birlikte petrol fiyatlarındaki değişimler, ülkelerin ekonomik faaliyetlerini etkilemektedir. Çünkü petrol ekonomik kalkınma ve gelişme açısından ülkeler için oldukça önemlidir. Bazı ülkeler petrol ihracatçısı durumundayken bazıları da petrol ithal etmektedir. Dolayısıyla petrol fiyatlarındaki değişimler ülkelerin makroekonomik değişkenlerini etkilemenin yanında finansal piyasalar üzerinde de önemli bir etkiye sahiptir. Son yıllarda, katılım endeksleri, yatırımcılar ve fon yöneticileri için önem kazanmıştır. Çünkü yatırımcılar, yatırım kararlarını verirken sadece makroekonomik değişkenleri dikkate almazlar bunun yanında yatırımcıların duygularl, dini hassasiyetleri, düşünceleri ve tutumları da aldıkları finansal kararları etkilemektedir. Bu bağlamda araştırmanın amacı, ham petrol fiyatlarının katılım endeksleri üzerindeki etkilerini test etmektir. Araştırmada ham petrol fiyatlarının, katılım endeksleri üzerindeki etkileri Lee-Strazicich Birim Kök Testi ve Toda-Yamamoto Nedensellik Testi ile incelenmiş ve sonuçlar zaman serisi analiz yöntemleri ile ortaya konmuştur. Elde edilen sonuçlara göre araştırmanın gerçekleştirildiği dönemlerde ham petrol fiyatlarının, Katılım -30 endeksini ve Katılım -Model Portföy endeksini etkilemediği, ancak ham petrol fiyatlarının Katılım -50 endeksini etkilediği tespit edilmiştir.

\author{
ANAHTAR KELIMELER
}

Ham Petrol, Katılım Endeksleri, Lee-Strazicich Birim Kök Testi, Toda-Yamamoto Nedensellik

\begin{abstract}
With globalization, changes in oil prices affect the economic activities of countries. Because oil is very important for countries in terms of economic development and development, while some countries are oil exporters, others import oil. Therefore, the changes in oil prices have an important effect on the financial markets as well as affecting the macroeconomic variables of countries.In recent years, participation indices have gained importance for investors and fund managers. Because investors not only take into account macroeconomic variables while making their investment decisions, but also their emotions, religious sensibilities, thoughts and attitudes affect the financial decisions they take. In this context, the purpose of the research is to discover the effects of crude oil prices on participation indices. In the research, the effects of crude oil prices on participation indices were examined by Lee-Strazicich Unit Root Test and Toda-Yamamoto Causality Test and the results were presented by time series analysis methods. According to the results obtained, it was determined that crude oil prices did not affect the Participation -30 index and Participation -Model Portfolio index, but crude oil prices affected the Participation -50 index.
\end{abstract}

\section{KEYWORDS}

Crude Oil, Participation Indices, Lee-Strazicich Unit Root Test, Toda-Yamamoto Causality

\begin{tabular}{|c|c|c|}
\hline \multicolumn{2}{|r|}{$\begin{array}{c}\text { Makale Geliş Tarihi / Submission Date } \\
23.02 .2021\end{array}$} & $\begin{array}{c}\text { Makale Kabul Tarihi / Date of Acceptance } \\
26.04 .2021\end{array}$ \\
\hline Attf & $\begin{array}{l}\text { Alptürk, Y., Tunçel, M. B., Yılmaz, T } \\
\text { İlişkinin Tespitine Yönelik Bir Araştı1 } \\
\text { 162-172. }\end{array}$ & $\begin{array}{l}\text { Tam Petrol Fiyatları ve Katılım Endeksleri Arasındaki } \\
\text { i Sosyal Bilimler Meslek Yüksekokulu Dergisi, } 24 \text { (1), }\end{array}$ \\
\hline
\end{tabular}

\footnotetext{
${ }^{1} \mathrm{Bu}$ çalışma 5. Lisansüstü İşletme Öğrencileri Sempozyumunda sunulmak üzere kabul edilen bildirinin genişletilmiş ve güncellenmiş halidir.

* Öğr. Gör., yasaralpturk@ksu.edu.tr, Sütçü İmam Üniversitesi, Sosyal Bilimler MYO, Muhasebe ve Vergi Bölümü, ORCID: 0000-0003-0063-4479

** Öğr.Gör., mbtuncel@ sirnak.edu.tr, Şırnak Üniversitesi, Şırnak MYO, Muhasebe ve Vergi Bölümü, ORCID: 0000-0001-8554-8080

*** Dr. Öğr. Üyesi, tayfunyilmaz@ mehmetakif.edu.tr, Mehmet Akif Ersoy Üniversitesi, İIBB, İşletme Bölümü, ORCID: 0000-0002-7127-2017

***** Prof. Dr., ismailbekci@sdu.edu.tr, Süleyman Demirel Üniversitesi İ̈BF, İşletme Bölümü, ORCID: 0000-0002-9862-737X
} 


\section{GİRIŞ}

Dünyada ve Türkiye'deki şehirleşme, sanayileşme ve iktisadi kalkınma süreci, enerji ihtiyacındaki artış1 beslemeye devam etmektedir. Nitekim British Petrol (BP) 2019 enerji istatistik raporuna göre; dünya birincil enerji tüketimi 2018 yılında \%2,9 oranında artarak son 10 yılın en büyük büyümesini gerçekleştirmiştir. Aynı dönemde günlük 0,5 milyon varil artış ile petrol tüketimi de yine son 10 yılın en yüksek değerine ulaşmıştır (BP, 2019: 2-4). 2019 y1lında birincil enerji tüketimindeki büyüme ise \%1,3 oranında gerçekleşmiş, petrol tüketimi de günlük 0,9 milyon varil artış kaydetmiştir. Ayrıca tüm sıvı yakıtlara olan günlük talep 1,1 milyon varil yükselerek ilk defa günde 100 milyon varili aşmıştır (BP, 2020: 3).

Dünya genelinde teknolojinin gelişmesiyle birlikte yenilenebilir enerji maliyetlerinde meydana gelen düşüş ve arz-talep dengesinde meydana gelen değişiklikler, petrol fiyatlarında volatiliteye yol açmaktadır. Ayrıca petrol ihraç eden ülkelerin ekonomik durumlarındaki dalgalanmaların yanı sıra; İran, Suriye ve Libya gibi ülkelerdeki jeopolitik risklerden kaynaklanan belirsizlikler de bu yakıtın üretimine ilişkin tahminleri zorlaştırmaktadır. Dolayısıyla ekonomik ve diğer faktörler enerji güvenliği açısından belirleyici rol oynamaktadır (KPMG, 2019: 3).

Petrol fiyatları, ülke ekonomilerini etkileyen temel değişkenler arasında yer almaktadır. Ancak bu etki, petrol ihraç eden ve petrol ithal eden ülkelere göre değişir. Çünkü, petrol ihraç eden ülkelerin en önemli gelir kaynağını söz konusu yakıt oluşturduğu için, petrol fiyatlarının artması bu ülkeleri pozitif yönde etkilemekte ve gelir kaynaklarında belirgin bir artış meydana getirebilmektedir. Diğer taraftan petrol ithal eden ülkeler açısından bakıldığında ise fiyatların yükselmesi maliyetlerin artmasına yol açarak milli gelir üzerinde azaltıcı bir etki yaratabilmektedir. Petrol fiyatlarının düşmesi ise petrol ihraç eden ülkelerin gelirlerini negatif yönde etkilerken; ithal eden ülkelerin gelirleri üzerinde olumlu bir sonuç ortaya çıkarmaktadır (Özmerdivanlı, 2014: 3).

Temel emtialar haricinde petrolün diğer emtialara göre etki alanı ve etki derecesi daha büyüktür. Çünkü petrol sadece bir yakıt değil; aynı zamanda petrokimya endüstrisinin hammadde girdisidir. Dolayısıyla petrol fiyatlarındaki bir değişme nakit akışlarına ve karlılık oranlarına yansıyabilmektedir (Karcıoğlu vd., 2017: 301).

Türkiye Cumhuriyeti Enerji ve Tabii Kaynaklar Bakanlığı tarafından açıklanan verilere göre; 2019 yılında 31 milyon ton ham petrol ithalatının yanı sıra 13,7 milyon ton da petrol ürünü ithal edilmiştir (T.C. Enerji ve Tabii Kaynaklar Bakanlığı, 2019). Üretilen miktar talebi karşlayacak büyüklükte olmadığı için Türkiye zorunlu olarak ham petrol ve türevlerinin büyük bir kısmını ithal ederek talebini karşılamaktadır. Bu bağlamda petrol fiyatlarındaki değişim ve oynaklık, özellikle sanayi sektöründe önemli etkiler meydana getirebilmektedir (Yıldırım vd., 2014: 94).

Hisse senedi getiri endekslerini etkileyen değişkenlerin tespit edilmesi finans literatüründe önceden beri süregelen ve devamlılı̆̆ını sürdüren bir konudur. Çünkü portföy yöneticileri ve yatırımcılar açısından hisse senedi getirilerini etkileyen değişkenleri bilmek yatırım kararlarında önemli rol oynamaktadır (Güler vd., 2010: 297). Bu çerçevede, Türkiye'de petrol fiyatlarındaki değişimin hisse senetlerinin fiyatlarını ne yönde etkilediğinin tespit edilmesi yatırımcılar, yöneticiler, karar alıcılar ve piyasanın diğer aktörleri açısından yol gösterici olacaktır (Özmerdivanlı, 2014: 3).

$\mathrm{Bu}$ çalışmanın amacı; petrol fiyatları ve katılım endeksleri arasındaki ilişkiyi ekonometrik olarak test etmektir. Söz konusu değişkenler arasındaki bağıntıyı ele alan çalışmalar incelenmiş ve sınırlı sayıda olduğu görülmüştür. Günümüzde fiyat ve yatırım araçları ilişkisi hala güncelliğini koruyan bir konudur. Yatırım kararlarını verirken dini hassasiyetlerini de dikkate alan yatıımcılar açısından, katılım endeksleri ve bu endeksleri etkileyen makro ekonomik değişkenler önem arz etmektedir. Buna ek olarak endeksleri oluşturan şirketlerin petrolü faaliyetlerinde kullanmaları dolayısıyla ham petrol fiyatlarında meydana gelen artışlar şirketlerin maliyet kalemlerini artırarak kârlıkları üzerinde baskı oluşturacaktır. Bu durum şirketlerin finansal performanslarını negatif etkileyerek şirketlerin hisse senetleri üzerinde olumsuz bir etkiye sebep olabilir. Ayrıca Katılım -30 endeksinin BIST Sınai Endeksinin kapanış değeriyle hesaplanmaya başlamış olması nedeniyle petrol fiyatlarındaki değişimlerin, hisse senetlerinin fiyatlarını ve yatırımları etkileyebileceği düşünülmektedir. Diğer taraftan özellikle petrol zengini Arap ülkelerinden, Borsa İstanbul'a gelecek olan yatırımlarda bu ülkelerdeki yatırımcıların dini hassasiyetlerinden dolayı katılım endekslerindeki şirketlere yatırım yapmaları beklenmektedir.

Çalışmada güncel veri ve analiz yöntemleri kullanılarak ham petrol fiyatları ve katılım endeksleri arasında ilişki olup olmadığı tespit edilmeye çalışılmıştır. Bu yönüyle çalışma ilk olma özelliği gösterip bu anlamda literatüre katkı yapması beklenmektedir. Araştırmanın ikinci bölümünde petrol fiyatlarının hisse senetleri ile olan ilişkilerini tespit etmeye yönelik literatürde yer alan çalışmalar özetlenmiştir. 


\section{LITERATÜR ARAŞTIRMASI}

Literatürde petrol fiyatları ve hisse senetleri endeksleri arasındaki ilişkinin ampirik olarak incelendiği çeşitli çalışmalar bulunmaktadır. Finansal piyasaların önemli bir parçasını oluşturan hisse senetleri piyasalarına yönelik yapılan tahminlerde, petrol fiyatlarının bir değişken olarak seçilmesi çok sayıda araştırmaya konu olmuştur. Bu kapsamda, ham petrol fiyatları ve hisse senetlerinin getirileri arasındaki ilişkileri inceleyen bazı çalışmalara ait özet bilgiler gelişmiş ülkeler, gelişmekte olan ülkeler ve Türkiye şeklinde sınıflandırılarak sunulmuştur.

\section{Tablo 1. Gelişmiş Ülkeler Üzerine Yapılan Çalışmalar}

\begin{tabular}{|c|c|c|c|}
\hline Yazarlar & Ülke & Yöntem & Bulgular \\
\hline $\begin{array}{l}\text { Kaneko \& Lee } \\
\quad(1995)\end{array}$ & ABD, Japonya & VAR & $\begin{array}{l}\text { Petrol fiyatlarındaki değişiklik, Japonya'da } \\
\text { hisse senetleri üzerinde önemli bir etkisi } \\
\text { bulunmaktadır. }\end{array}$ \\
\hline $\begin{array}{l}\text { Jones \& Kaul } \\
\quad(1996)\end{array}$ & $\begin{array}{l}\text { İngiltere, Kanada, } \\
\text { Japonya, ABD }\end{array}$ & $\begin{array}{c}\text { Granger } \\
\text { nedensellik }\end{array}$ & $\begin{array}{l}\text { ABD ve Kanada'daki hisse senetlerinin petrol } \\
\text { fiyatlarında meydana gelen değişikliklere tepki } \\
\text { verdiği ancak Japonya ve İngiltere'nin petrol } \\
\text { fiyatı şoklarına daha çok tepki gösterdiği tespit } \\
\text { edilmiştir. }\end{array}$ \\
\hline Huang vd. (1996) & $\mathrm{ABD}$ & VAR modeli & $\begin{array}{l}\text { Petrol fiyatlarıyla, hisse senetleri endeksleri } \\
\text { arasında önemli bir ilişki tespit edilememiştir. }\end{array}$ \\
\hline Sadorsky (1999) & $\mathrm{ABD}$ & VAR modeli & $\begin{array}{l}\text { Petrol fiyatlarındaki değişiklikler hisse } \\
\text { senetlerinin getirilerinde meydana gelen } \\
\text { hareketleri açıklamada önemli bir etkiye } \\
\text { sahiptir. }\end{array}$ \\
\hline $\begin{array}{l}\text { Faff \& Brailsford } \\
\qquad(1999)\end{array}$ & Avustralya & $\begin{array}{l}\text { Finansal varlık } \\
\text { fiyatlama modeli }\end{array}$ & $\begin{array}{l}\text { Petrol fiyatlarıyla, çeşitlendirme yapılmış ürün } \\
\text { sektörleri arasında anlamlı ve pozitif ilişki } \\
\text { bulunmuştur. }\end{array}$ \\
\hline El-Sharif vd. (2005) & İngiltere & $\begin{array}{l}\text { Çoklu faktör } \\
\text { analizi }\end{array}$ & $\begin{array}{l}\text { İngiltere'de ham petrol fiyatındaki oynaklığın } \\
\text { gaz ve petrol sektörü içindeki hisse senetleri } \\
\text { üzerinde doğrudan etkisi bulunduğu tespit } \\
\text { edilmiştir. }\end{array}$ \\
\hline Odusami (2009) & $\mathrm{ABD}$ & GARCH modeli & $\begin{array}{l}\text { Petrol fiyatlarındaki şokların hisse senetleri } \\
\text { üzerinde negatif, lineer olmayan bir etkiye sahip } \\
\text { olduğu tespit edilmiştir. }\end{array}$ \\
\hline $\begin{array}{l}\text { Chiou \& Lee } \\
\text { (2009) }\end{array}$ & $\mathrm{ABD}$ & ARJI modeli & $\begin{array}{l}\text { Petrol fiyatlarında oluşan yüksek } \\
\text { dalgalanmaların S\&P500 endeksi üzerinde } \\
\text { negatif bir etkisi olduğu bulunmuştur. }\end{array}$ \\
\hline Roselee vd. (2009) & $\begin{array}{l}\text { ABD, İngiltere, } \\
\text { Hindistan }\end{array}$ & VAR modeli & $\begin{array}{l}\text { Faiz oranları ve petrol fiyatları ile petrol hisse } \\
\text { senetleri endeksleri arasında uzun ve kısa } \\
\text { dönemde istatistiki olarak anlamlı bir ilişki } \\
\text { bulunmuştur. }\end{array}$ \\
\hline $\begin{array}{l}\text { Hacıhasanoğlu \& } \\
\text { Soytaş (2011) }\end{array}$ & $\mathrm{ABD}$ & Toda-Yamamoto & $\begin{array}{l}\text { Petrol fiyatlarıyla, hisse senetleri arasındaki } \\
\text { ilişkinin çeşitli faktörlerin etkisi nedeniyle } \\
\text { yapısal değişiklikler gösterebildiği tespit } \\
\text { edilmiştir. }\end{array}$ \\
\hline Le \& Chang (2011) & $\begin{array}{l}\text { Singapur, Japonya, } \\
\text { Kore ve Malezya }\end{array}$ & VAR Modeli & $\begin{array}{l}\text { Borsaların petrol fiyat şoklarına tepkisi ülke } \\
\text { piyasalarına göre değişim göstermektedir. }\end{array}$ \\
\hline
\end{tabular}


Tablo 2. Gelişmekte Olan Ülkeler Üzerine Yapılan Çalışmalar

\begin{tabular}{|c|c|c|c|}
\hline Yazarlar & Ülke & Yöntem & Bulgular \\
\hline $\begin{array}{l}\text { Hammoudeh \& } \\
\text { Eleisa (2004) }\end{array}$ & $\begin{array}{l}\text { Körfez Arap Ülkeleri } \\
\text { İşbirliğine üye ülkeler }\end{array}$ & VAR Modeli & $\begin{array}{l}\text { Suudi Arabistan piyasasında hisse senedi } \\
\text { fiyatlarıyla, petrol fiyatları arasında çift yönlü } \\
\text { bir ilişki tespit edilmiştir. }\end{array}$ \\
\hline Maghyereh (2004) & $\begin{array}{l}\text { Gelişmekte olan } 22 \\
\text { ülke }\end{array}$ & VAR Modeli & $\begin{array}{l}\text { Hisse senedi getirileri üzerinde petrol fiyat } \\
\text { şoklarının etkisi olmadığı tespit edilmiştir. }\end{array}$ \\
\hline $\begin{array}{l}\text { Basher \& Sadorsky } \\
\quad \text { (2006) }\end{array}$ & $\begin{array}{l}21 \text { Gelisşmekte Olan } \\
\text { Ülke }\end{array}$ & $\begin{array}{l}\text { Çoklu Faktör } \\
\text { Analizi }\end{array}$ & $\begin{array}{l}\text { Gelişmekte olan ülke piyasalarında petrol } \\
\text { fiyatlarında meydana gelen artışların hisse } \\
\text { senetlerinin fiyatları üzerinde büyük ve pozitif } \\
\text { bir etkiye sahip olduğu tespit edilmiştir. }\end{array}$ \\
\hline $\begin{array}{l}\text { Maghyereh \& Al- } \\
\text { Kandari (2007) }\end{array}$ & $\begin{array}{l}\text { Körfez Arap Ülkeleri } \\
\text { İşbirliğine üye ülkeler }\end{array}$ & $\begin{array}{l}\text { Doğrusal } \\
\text { Olmayan } \\
\text { Eşbütünleşme }\end{array}$ & $\begin{array}{l}\text { Analize tabi tutulan değişkenlerin aralarında, } \\
\text { uzun dönemli doğrusal olmayan bir ilişki } \\
\text { bulunmuştur. }\end{array}$ \\
\hline Cong vd. (2008) & Çin & VAR Modeli & $\begin{array}{l}\text { Petrol fiyatlarında meydana gelen şokların } \\
\text { Çin'deki üretim ve bazı petrol şirketlerinin hisse } \\
\text { senetleri dışında diğer sektörleri etkilemediği } \\
\text { sonucu tespit edilmiştir. }\end{array}$ \\
\hline Park \& Ratti (2008) & 14 geliş̧şş ülke & VAR Modeli & $\begin{array}{l}\text { Hisse senetlerinin getirileri üzerinde, petrol } \\
\text { fiyatlarında meydana gelen şokların önemli bir } \\
\text { etkiye sahip olduğu bulunmuştur. }\end{array}$ \\
\hline Gay (2008) & $\begin{array}{l}\text { Brezilya, Çin, } \\
\text { Hindistan, Rusya, }\end{array}$ & ARIMA Modeli & $\begin{array}{l}\text { Pay senetleri ile petrol fiyatları arasında } \\
\text { herhangi bir ilişsi tespit edilememiştir. }\end{array}$ \\
\hline Al-Fayoumi (2009) & $\begin{array}{l}\text { Türkiye, Tunus ve } \\
\text { Ürdün }\end{array}$ & $\begin{array}{l}\text { VEC Johansen } \\
\text { Eşbütünleşme, }\end{array}$ & $\begin{array}{l}\text { Hisse senetleri üzerinde, petrol fiyatlarında } \\
\text { meydana gelen değişikliklerin herhangi bir } \\
\text { etkisi bulunmamaktadır. }\end{array}$ \\
\hline $\begin{array}{l}\text { Narayan \& Narayan } \\
\text { (2009) }\end{array}$ & Vietnam & $\begin{array}{l}\text { Johansen } \\
\text { Eşbütünleşme, } \\
\text { VEC }\end{array}$ & $\begin{array}{l}\text { Hisse senetleri üzerinde petrol fiyatlarının } \\
\text { pozitif etkileri olduğu ortaya konmuştur. }\end{array}$ \\
\hline $\begin{array}{l}\text { Arouri \& Rault } \\
\quad(2009)\end{array}$ & $\begin{array}{c}\text { Arap Körfez } \\
\text { İş birliği üyesi ülkeler }\end{array}$ & Panel Nedensellik & $\begin{array}{l}\text { Suudi Arabistan hisse senetlerinin fiyatları ile } \\
\text { petrol fiyatları arasında karş1lıklı nedensellik } \\
\text { tespit edilmiştir. }\end{array}$ \\
\hline Chittedi (2012) & Hindistan & ARDL Modeli & $\begin{array}{l}\text { Hisse senetlerinin fiyatlarındaki oynaklık petrol } \\
\text { fiyatları üzerinde önemli bir etkiye sahiptir. }\end{array}$ \\
\hline Adaramola (2012) & Nijerya & $\begin{array}{l}\text { Johansen } \\
\text { Eşbütünleşme, } \\
\text { VEC Modeli }\end{array}$ & $\begin{array}{l}\text { Petrol fiyatı şoklarından hisse senetlerinin } \\
\text { getirilerine doğru güçlü nedensellik } \\
\text { bulunmuştur. }\end{array}$ \\
\hline $\begin{array}{l}\text { Gündoğan \& Tok } \\
\text { (2019) }\end{array}$ & $\begin{array}{l}15 \text { Ülkenin Sanayi } \\
\text { Üretim Endeksleri }\end{array}$ & $\begin{array}{l}\text { Pedroni Panel } \\
\text { Eşbütünleşme }\end{array}$ & $\begin{array}{l}\text { Petrol fiyatları ve sanayi üretim endeksleri } \\
\text { arasında, istatistiki olarak anlamlı ve pozitif } \\
\text { uzun dönemli ilişki bulunmuştur. }\end{array}$ \\
\hline Alsu (2019) & $\begin{array}{l}\text { Türkiye, Birleşik } \\
\text { Arap Emirlikleri, } \\
\text { Ürdün, Suudi } \\
\text { Arabistan, Bahreyn, } \\
\text { Katar ve Kuveyt }\end{array}$ & $\begin{array}{l}\text { Hatemi-J } \\
\text { Eşbütünleşme ve } \\
\text { Maki } \\
\text { Eşbütünleşme, } \\
\text { Toda-Yamamoto } \\
\text { ve Fourier Toda- } \\
\text { Yamamoto } \\
\text { Nedensellik }\end{array}$ & $\begin{array}{l}\text { Suudi Arabistan haricindeki ülkelerin endeks ve } \\
\text { petrol fiyatları arasında eş bütünleşik uzun } \\
\text { dönemli ilişki bulunduğu ayrıca kısa dönemde } \\
\text { petrol fiyatlarından Kuveyt, Katar, Birleşik } \\
\text { Arap Emirlikleri ve Bahreyn, endekslerine } \\
\text { doğru bir nedensellik ilişkisi olduğu tespit } \\
\text { edilmiştir. }\end{array}$ \\
\hline
\end{tabular}


Tablo 3. Türkiye Üzerine Yapılan Çalışmalar

\begin{tabular}{|c|c|c|c|}
\hline Yazarlar & Ülke & Yöntem & Bulgular \\
\hline $\begin{array}{l}\text { İşcan } \\
(2010)\end{array}$ & Türkiye & $\begin{array}{l}\text { Johansen } \\
\text { Eşbütünleşme, } \\
\text { Granger } \\
\text { Nedensellik }\end{array}$ & $\begin{array}{l}\text { Hisse senetlerinin fiyatlarıyla, petrol fiyatları } \\
\text { arasında herhangi bir ilişkinin bulunmadığı } \\
\text { tespit edilmiştir. }\end{array}$ \\
\hline $\begin{array}{l}\text { Kapusuzoğlu } \\
\quad(2011)\end{array}$ & Türkiye & $\begin{array}{c}\text { Johansen } \\
\text { Eşbütünleşme, } \\
\text { VEC modeli }\end{array}$ & $\begin{array}{l}\text { Hisse senetlerinden, petrol fiyatlarına doğru bir } \\
\text { nedensellik bulunmuştur. İlişki tek yönlüdür. }\end{array}$ \\
\hline $\begin{array}{l}\text { Şener vd. } \\
\text { (2013) }\end{array}$ & Türkiye & $\begin{array}{l}\text { Granger-Yoon } \\
\text { Saklı } \\
\text { Eşbütünleşme }\end{array}$ & $\begin{array}{l}\text { Petrol fiyatları ve hisse senetleri arasında uzun } \\
\text { dönemde bir ilişki bulunmuştur. }\end{array}$ \\
\hline $\begin{array}{l}\text { Ünlü \& Topçu } \\
\text { (2012) }\end{array}$ & Türkiye & $\begin{array}{l}\text { Johansen } \\
\text { Eşbütünleşme, } \\
\text { VEC, Toda- } \\
\text { Yamamoto } \\
\text { Nedensellik }\end{array}$ & $\begin{array}{l}\text { Petrol fiyatları hisse senedi piyasasını pozitif } \\
\text { etkiler. }\end{array}$ \\
\hline $\begin{array}{l}\text { Abdioğlu \& } \\
\text { Değirmenci } \\
\quad(2014)\end{array}$ & Türkiye & $\begin{array}{l}\text { Granger } \\
\text { Nedensellik } \\
\text { Analizi }\end{array}$ & $\begin{array}{l}\text { Alt sektörlerde hisse senetlerinden, petrol } \\
\text { fiyatlarına doğru nedensellik bakımından tek } \\
\text { yönlü bir ilişkisi bulunmuştur. }\end{array}$ \\
\hline $\begin{array}{l}\text { Yıldırım vd. } \\
\text { (2014) }\end{array}$ & Türkiye & $\begin{array}{c}\text { Regresyon analizi } \\
\text { Johansen-Juselius } \\
\text { Eşbütünleşme, } \\
\text { Granger } \\
\text { nedensellik } \\
\end{array}$ & $\begin{array}{l}\text { Petrol endeksinden, tek yönlü olarak sınai } \\
\text { endeksine doğru nedensellik bulunurken, petrol } \\
\text { fiyatlarının da hisse senetlerini pozitif olarak } \\
\text { etkilediği bulunmuştur. }\end{array}$ \\
\hline $\begin{array}{l}\text { Özmerdivanlı } \\
\text { (2014) }\end{array}$ & Türkiye & $\begin{array}{l}\text { Granger } \\
\text { eşbütünleşme ve } \\
\text { nedensellik }\end{array}$ & $\begin{array}{l}\text { Petrol fiyatlarıyla, BIST100 kapanış endeks } \\
\text { fiyatları arasında uzun dönemli ilişki } \\
\text { bulunmuştur. }\end{array}$ \\
\hline $\begin{array}{c}\text { Kendirli \& } \\
\text { Çankaya } \\
(2016) \\
\end{array}$ & Türkiye & $\begin{array}{l}\text { Granger } \\
\text { Nedensellik }\end{array}$ & $\begin{array}{l}\text { XULAS endeksinden ham petrol fiyatlarına } \\
\text { doğru tek yönlü bir ilişsinin bulunduğu ortaya } \\
\text { konmuştur. }\end{array}$ \\
\hline $\begin{array}{l}\text { Öget \& Şahin } \\
\quad(2017)\end{array}$ & Türkiye & $\begin{array}{c}\text { Johansen } \\
\text { Eşbütünleşme }\end{array}$ & $\begin{array}{l}\text { Ham petrol fiyatlarındaki değişikliklerin hisse } \\
\text { senetleri üzerinde kalıcı etkiler bıraktığı tespit } \\
\text { edilmiştir. }\end{array}$ \\
\hline $\begin{array}{c}\text { Syzdykova } \\
\text { Oralbaykızı (2019) }\end{array}$ & Türkiye & VAR modeli & $\begin{array}{l}\text { Petrol fiyat değişimlerinin etkisi sektörlere göre } \\
\text { değişmektedir, }\end{array}$ \\
\hline $\begin{array}{l}\text { Yıldırım \& } \\
\text { İşcanoğlu Çekiç } \\
\text { (2019) }\end{array}$ & Türkiye & $\begin{array}{l}\text { Granger } \\
\text { Nedensellik, } \\
\text { Simetrik ve } \\
\text { Asimetrik } \\
\text { Nedensellik }\end{array}$ & $\begin{array}{l}\text { BIST100 endeksi ile ham petrol fiyatları } \\
\text { arasında doğrusal olmayan çift yönlü } \\
\text { nedensellik tespit edilmiştir. Ayrıca } \\
\text { BIST100'den ham petrol fiyatlarına doğru } \\
\text { asimetrik nedensellik bakımından tek yönlü bir } \\
\text { ilişki bulunmuştur. }\end{array}$ \\
\hline $\begin{array}{l}\text { Kırıcı Altınkeski } \\
\& \text { Çevik (2019) }\end{array}$ & Türkiye & VAR modeli & $\begin{array}{l}\text { BIST } 100 \text { endeksinin petrol fiyat şoklarından } \\
\text { etkilendiğini göstermektedir. }\end{array}$ \\
\hline $\begin{array}{c}\text { Konuşkan \& } \\
\text { Kocabiyık (2019) }\end{array}$ & Türkiye & $\begin{array}{l}\text { Sınırlandırılmamış } \\
\text { VAR, Granger } \\
\text { nedensellik }\end{array}$ & $\begin{array}{l}\text { Petrol fiyatları ile BİST100 endeksi arasında } \\
\text { uzun dönemde bir ilişki bulunmadığı sonucuna } \\
\text { ulaşılmış, petrol fiyatlarından BIST100'e doğru } \\
\text { bir Granger nedensellik de tespit edilememiştir. }\end{array}$ \\
\hline
\end{tabular}




\section{ARAŞTIRMANIN TASARIM VE YÖNTEMI}

Ham petrol fiyatları ve katılım endeksleri arasındaki ilişkinin araştıııldığı çalışmada zaman serisi analizlerinden yararlanılmıştır. Zaman serisi analizleri ilk başlarda iktisadi araştırmalar için kullanılsa da zaman içerisinde finans araştırmalarında da önem kazanmış ve kullanılmaya başlamıştır.

\subsection{Araştırmanın Amacı}

$\mathrm{Bu}$ araştırmanın amacı, ham petrol fiyatları ile İslami prensiplere göre oluşturulan ve gelişimi Türkiye'de yeni olan katılım endeksleri arasındaki ilişkinin ekonometrik olarak araştırılmasıdır. Katılım -30 endeksi için 2011-2019 arası haftalık frekanstaki verileri, Katılım -50 ile Katılım Model Portföy endeksleri içinse 20142019 arası haftalık frekanstaki veriler kullanılarak ham petrol fiyatlarıyla, katılım endeksleri arasında bir ilişki bulunup bulunmadığını incelemektir.

\subsection{Veri Seti}

Araştırmada Ham Petrol Fiyatları ile Katılım -30 endeksi için 2011-2019 arası haftalık frekanstaki veriler (444 gözlem) kullanırken, Katılım -50 endeksi ile Katılım -Model Portföy endeksi içinse 2014-2019 tarihleri arası, haftalık frekanstaki veriler (286 gözlem) kullanılmıştır. Katılım 30 endeksi ana faaliyet alanı ve finansal kriterleri bakımından katılım endeksinde olmaya hak kazanmış, Yıldız Pazar ve Ana Pazar şirketlerinden oluşmuş̧tur. Katılım -50 endeksi de Katılım -30 endeksinde olduğu gibi ana faaliyet alanı ve finansal kriterleri bakımından seçilmiş 50 Yıldız ve Ana şirketinin bir araya getirilmesiyle oluşturulmuştur. Katılım -Model Portföy endeksinde yer alacak şirketler ise Katılım -50 endeksinde bulunan şirketler arasından seçilir. Veri setlerine ilişkin dönem aralıklarının birbirinden farklı olmasının sebebi; ilgili endekslerin hesaplanmaya başlama tarihlerinin farklı olmasından kaynaklanmaktadır. Çalışmada bağımlı değişken olarak KATLM30, KAT50 ve KATMP endeksleri bağımsız değişken ise brent petrol fiyatları kullanılmıştır.

Tablo 4. Veri Seti

\begin{tabular}{|c|c|c|c|c|}
\hline Değişkenler & Değişkenlerin Açıklamaları & Dönem Aralı̆̆ı & Veri Periyodu & Kaynaklar \\
\hline KATLM30 & Katılım -30 Endeksi & $2011-2019$ & & investing.com \\
\hline KAT50 & Katılım -50 Endeksi & $2014-2019$ & \multirow{3}{*}{ Haftalık } & investing.com \\
\cline { 2 - 3 } \cline { 5 - 5 } KATMP & Katılım -Model Portföy Endeksi & $2014-2019$ & & tr.tradingview.com \\
\hline BRENT & Brent Petrol Fiyatları & $2011-2019$ & & investing.com \\
\hline
\end{tabular}

Şekil 1. Değişkenlerin Zaman Serisi Grafikleri
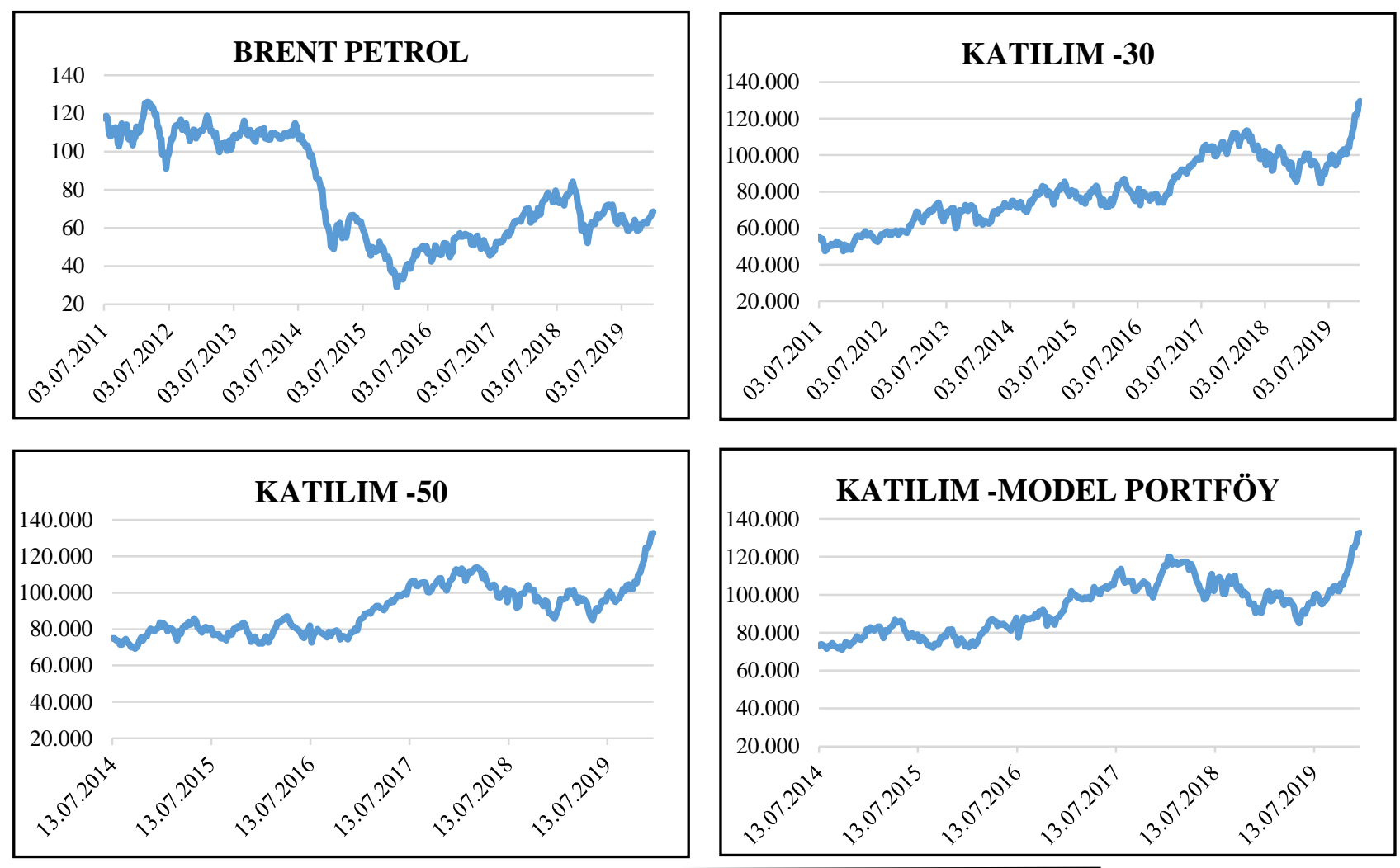

Selçuk Üniversitesi Sosyal Bilimler Meslek Yüksekokulu Dergisi, Yıl: 2021 Cilt: 24 Sayı:1 


\subsection{Araştırmanın Hipotezleri}

Araştırmada, veri setlerinde kırılmaların yaşanıp yaşamadığı, birim kök bulunup bulunmadığı, veri setlerinin trend içerip içermediği ve değişkenlerin arasında bir ilişki bulunup bulunmadığıyla ilgili olarak test edilecek hipotezler şu şekildedir:

$\boldsymbol{H}_{0}$ : Ham Petrol Fiyatlartyla, KATILIM endeksleri arasında bir nedensellik ilişsisi bulunmamaktadır.

$\boldsymbol{H}_{1}$ : Ham Petrol Fiyatlarıyla, KATILIM endeksleri arasında bir nedensellik ilişkisi bulunmaktadır.

\subsection{Araştırmanın Metodolojisi}

Seçilen ham petrol fiyatları değişkeniyle, katılım endeksleri ilişkisini incelemek üzere zaman serisi analizlerinden yararlanılmıştır. Değişkenlerin arasında bulunan ilişkileri araştırmak için ilk yapılması gereken değişkenlerin durağanlıklarının tespit edilmesidir. Bu amaçla verilere ilk olarak yapısal kırılmaları da dikkate alan Lee ve Strazicich (2003) birim kök testleri uygulanmıştır. Ardından optimal gecikme uzunluğunun tespiti için Akaike Bilgi Kriteri (AIC) kullanılmış, son olarak da değişkenlerin arasında bir nedensellik olup olmadığı, nedensellik ilişkisi varsa bunların yönleri tespiti ikili analiz şeklinde Toda-Yamamoto yöntemi ile sınanmıştır.

\subsubsection{Lee-Strazicich Birim Kök Testi}

Lee ve Strazicich (2003) ekonometrik analizlerde zaman serilerinde tek bir kırılmayı dikkate almanın oldukça kısıtlayıcı bir tutum olduğunu belirterek, yapısal olarak iki kırılmaya izin veren alternatif bir test geliştirmişlerdir (Sivri, 2010: 226). LM birim kök testlerinde kullanılan denklem şu şekildedir;

$$
y_{1}=\delta Z_{t}+e_{t} \quad e_{t}=\beta e_{t-1}+\varepsilon_{t}
$$

Denklem (1)'de $Z_{t}$ dişsal değişkenler vektörü, $\varepsilon_{t} \sim$ iid $\left.N\left(0, \sigma^{2}\right)\right)$ özelliğine sahip olan hata terimlerini belirtir. Düzeyde iki değişikliğe yer veren A modeli $Z_{t}=\left[1, t, D_{1 t}, D_{2 t}\right]$ olarak ifade edilir. Burada; $D_{j t}=$ 1 için $t \geq T_{b j}+1, j=1,2$ ve farklı durumlar için 0 olur. $T_{b j}$ kırılma zamanını gösterir. Model(C) ise düzey ve trendde 2 değişiklik içerir. Model $Z_{t}=\left[1, t, D_{1 t}, D_{2 t}, D T_{1 t}, D T_{2 t}\right]$ şeklinde tanımlanır. Burada; $D T_{j t}=t-T_{b j}$ için $t \geq T_{b j}+1, \quad j=1,2$ ve diğer durumlar içinse 0 olur. Veri yaratma sürecinde (DGP) kırılmaları içeren temel hipotez altında $(\beta=1)$, alternatif hipotez ise $(\beta<1)$ şeklinde gösterilir.

Lee ve Strazicich, (LM) birim kök testlerinin istatistik değerini bulmak içinse aşağıdaki denklemden yararlanmışlardır:

$\Delta y_{t}=\delta^{\prime} \Delta Z_{t}+\varnothing \tilde{S}_{t-1}+u$

Burada $\tilde{S}_{t}=y_{t}-\tilde{\psi}_{x}-Z \delta, t=2, \ldots, T$; olup $\tilde{\delta}$ değeri $\Delta_{y t}$ 'nin regresyonundaki $\Delta Z_{t}$ ' den elde edilmiş katsayıları ifade eder. $\tilde{\psi}_{x}$, ise $y_{1}-Z_{1} \delta$ ile bulunur ve burada $y_{1}$ ve $Z_{1}$ belirtilen siraya göre $y_{t}$ ve $Z_{t}$ 'nin ilk elemanlarıdır (Lee ve Strazicich 2003: 1083).

Kırılma yaşanan dönemlerin tespiti yapılırken $\lambda_{i}=T B_{\mathrm{I}} / T, i \mathrm{i}=1,2$ formülünden yararlanılır. Buradaki $\mathrm{T}$, toplam gözlem sayısını ifade etmektedir. Testin minimum istatistik değerinin bulunduğu noktada birim kök (LM) testi için kırılma tarihleri tespit edilir. $L M_{\tau}={ }_{\lambda}^{\inf } \tilde{\tau}(\lambda)$ süreci izlenir. Burada " $\tau$ " t-istatistik değerini ifade eder (Esenyel, 2017: 47).

\subsubsection{Toda-Yamamoto Nedensellik Analizi}

Toda ve Yamamoto'nun (1995) geliştirdiği testinin ilk aşaması VAR modelinin yardımıyla gecikme uzunluğunun $(p)$ belirlenmesidir. Daha sonra da en yüksek bütünleşme derecesine $\left(d_{\max }\right)$ sahip olan değişken, gecikme uzunluğuna $(p)$ ilave edilir. Aşağıda verilen denklemler vasıtasıyla VAR modeli uygulanmaktadır (Doğan, 2017: 24). Toda-Yamamoto (1995) nedensellik analizinde kullanılan denklem aşağıdaki gibidir:

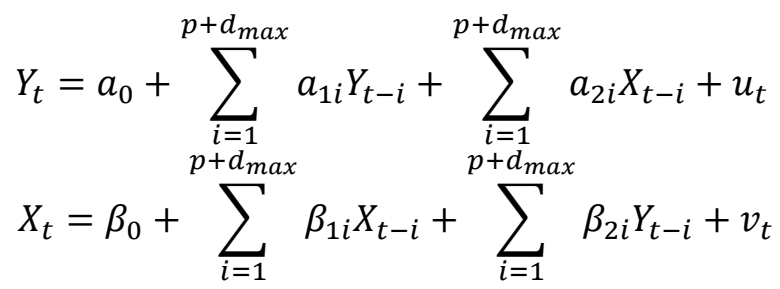

Toda-Yamamoto testinin temel hipotezi ve alternatif hipotezi şu şekilde kurulur:

$H_{0}: X$ değişseni $Y$ değişkeninin Granger nedeni değildir.

$H_{1}: X$ değişkeni $Y$ değişkeninin Granger nedenidir.

Toda-Yamamoto (1995) testinin başarılı olabilmesi için, serilerdeki bütünleşme derecelerinin $\left(d_{\max }\right)$ modelde ki uygun olan gecikme sayısının (k) doğru belirlenmesi gerekmektedir (Öner Badurlar, 2011:10). 


\section{ARAŞTIRMANIN BULGULARI}

Araştırmanın bu bölümünde ham petrol fiyatları ve katılım endeksleri arasındaki ilişkiyi ortaya koyabilmek amaciyla uygulanan testler ve elde edilen bulgular sunulmuştur.

\subsection{Lee-Strazicich Birim Kök Testi Sonuçları}

$\mathrm{Bu}$ araştırmada Lee-Strazicich (LS) testinde serilerdeki kırılmaları tespit edebilmek için (Model C) baz alınmıştır. Düzey değerlerinde durağanlaşmayan serilerin bir farkları alınarak yeniden (LS) birim kök testi yapılmıştır. Tespit edilen bulgular Tablo 5'de sunulmuştur.

Tablo 5. Lee- Strazicich Birim Kök Testi Sonuçları

\begin{tabular}{|c|c|c|c|c|c|c|}
\hline \multicolumn{7}{|c|}{ LS (Model-C) } \\
\hline \multirow[b]{2}{*}{ Değişkenler } & Düzey & \multirow[b]{2}{*}{$\begin{array}{c}\text { Düzeyin Kırılma } \\
\text { Tarihleri }\end{array}$} & \multirow[b]{2}{*}{$\begin{array}{c}\text { Kritik } \\
\text { Değerler }\end{array}$} & 1. Fark & \multirow[b]{2}{*}{$\begin{array}{c}\text { 1.Farkın Kırılma } \\
\text { Tarihleri }\end{array}$} & \multirow[b]{2}{*}{$\begin{array}{c}\text { Kritik } \\
\text { Değerler }\end{array}$} \\
\hline & $\begin{array}{c}\text { Test } \\
\text { İstatistiği }\end{array}$ & & & $\begin{array}{c}\text { Test } \\
\text { İstatistiği }\end{array}$ & & \\
\hline BRENT & $-3.112020 *$ & 22.02 .2015 & -4.11 & $-9.234932 *$ & 08.02 .2015 & -4.11 \\
\hline KATLM30 & $-3.638336^{*}$ & 23.09.2018 & -3.97 & $-14.71977 *$ & 26.07.2015 & -4.12 \\
\hline KAT50 & $-2.664577 *$ & 13.09 .2015 & -3.99 & $-11.90765^{*}$ & 20.09 .2015 & -3.98 \\
\hline КАТМР & $-3.385238 *$ & 06.09 .2015 & -3.99 & $-8.074017 *$ & 15.11 .2015 & -3.96 \\
\hline
\end{tabular}

*: \%5 seviyesinde anlamlıdır.

LS birim kök testi sonuçlarına göre BRENT, KATLM30, KAT50, KATMP değişkenlerinin düzey değerlerinde durağan olmadıkları; serilerin birinci farklarının alınmasından sonra durağan oldukları görülmüştür.

\subsection{Toda-Yamamoto Nedensellik Testi Sonuçları}

Seriler arasındaki bir nedensellik ilişkisini incelemek üzere Toda-Yamamoto testinden faydalanılmıştır. Araştırmada testler, değişkenler arasında ikili olarak tek tek uygulanmıştır. Toda-Yamamoto modeli uygulanırken, Akaike Bilgi Kriterine (AIC) göre serilerin gecikme uzunluğu (k) bulunurken öte yandan ise (LS) testine göre maksimum bütünleşme derecesi $\left(d_{\max }\right)\left(d_{\max }\right)$ bulunmuştur. Wald istatistiği modelde yer alan $(k)$ gecikme uzunluklarına uygulanarak nedensellik ilişkisinin bulunup bulunmadığ 1 tespit edilmeye çalışılmıştır.

Tablo 6. Toda-Yamamoto Nedensellik Testi Sonuçları

\begin{tabular}{|c|c|c|c|c|c|c|}
\hline $\begin{array}{c}\text { Bağımlı } \\
\text { Değişkenler }\end{array}$ & $\begin{array}{l}\text { Bağımsız } \\
\text { Değişken }\end{array}$ & $d_{\max }$ & $\mathbf{K}$ & $\begin{array}{c}\text { Ki-Kare Test } \\
\text { İstatistiği }\end{array}$ & $\begin{array}{l}\text { Ki-Kare } \\
\text { P-değeri }\end{array}$ & İlişkiler ve Yönü \\
\hline KATLM30 & \multirow{3}{*}{ BRENT } & 2 & 1 & 1.537515 & 0.2150 & ----- \\
\hline KAT50 & & 2 & 1 & 5.204656 & 0.0225 & $\mathrm{BRENT} \longrightarrow \mathrm{KAT} 50$ \\
\hline КАТМP & & 2 & 1 & 2.774286 & 0.0958 & ----- \\
\hline
\end{tabular}

*: \%5 düzeyinde istatistiki olarak anlamlıdır.

Tablo 6'da tespit edilmiş olan bulgular ışığında, BRENT serisinden KATLM30 ve KATMP serilerine doğru $\% 5$ anlamlılık seviyesinde kurulmuş olan temel hipotez reddedilmemiştir, ancak BRENT serisinden KAT50 serisine doğru $\% 5$ anlamlılık düzeyinde kurulmuş olan temel hipotezin ise reddedilmiş olduğu görülmektedir.

$H_{0}:$ Bă̆ımsız değişken bă̆ımlı değişkenin Granger nedeni değildir.

$H_{1}$ : Bă̆ımsız değişken bă̆ımlı değişkenin Granger nedenidir.

Diğer bir ifadeyle; BRENT serisinden KATLM30 ve KATMP serilerine doğru bir nedensellik ilişkisine rastlanmazken; BRENT serisinden KAT50 serisine doğru bir nedensellik ilişkisi mevcuttur. 
Tablo 7. Toda-Yamamoto Nedensellik Testi Sonuçları

\begin{tabular}{|c|c|c|c|c|c|c|}
\hline $\begin{array}{c}\text { Bağımlı } \\
\text { Değişken }\end{array}$ & $\begin{array}{c}\text { Bağımsız } \\
\text { Değişkenler }\end{array}$ & $\boldsymbol{d}_{\max }$ & $\mathbf{K}$ & $\begin{array}{c}\text { Ki-Kare Test } \\
\text { İstatistiği }\end{array}$ & $\begin{array}{c}\text { Ki-Kare } \\
\text { P-değeri }\end{array}$ & İlişkiler ve Yönü \\
\hline \multirow{3}{*}{ BRENT } & KATLM30 & 2 & 1 & 0.046520 & 0.8292 & ----- \\
\cline { 2 - 7 } & KAT50 & 2 & 1 & 0.101881 & 0.7496 & ---- \\
\cline { 2 - 7 } & KATMP & 2 & 1 & 0.386729 & 0.5340 & ---- \\
\hline
\end{tabular}

*: $\% 5$ düzeyinde istatistiki olarak anlamlıdır.

Tablo 7'de tespit edilmiş olan bulgular 1şı̆̆ında, KATLM30, KAT50 ve KATMP serilerinden BRENT serisine doğru \%5 anlamlılık düzeyinde kurulmuş olan temel hipotezin reddedilmediği görülmektedir.

$H_{0}:$ Bă̆ımsız değişken bă̆ımlı değişkenin Granger nedeni değildir.

$H_{1}:$ Bağımsız değişken bağımlı değişkenin Granger nedenidir.

Diğer bir ifadeyle KATLM30, KAT50 ve KATMP serilerinden BRENT serisine doğru bir nedensellik ilişkisine rastlanamamıştır. Katılım endekslerindeki fiyat değişimleri petrol fiyatlarını etkilememektedir.

\section{SONUÇ}

Araştırmanın konusunu oluşturan katılım endeksleri, faizsiz yatırım araçlarını hassasiyetleri ölçüsünde tercih eden yatırımcılar için önemli yatırım araçlarından bir tanesidir. Faizsiz hisselerden oluşan bu endeksler dini açıdan duyarlılığı yüksek yatırımcılar tarafından tercih edilirken ayrıca çeşitlendirme yapmak isteyen yatırımcılar için de alternatif oluşturmaktadır.

Fosil yakıtlar birçok endüstride kullanılmaktadır ve petrol, bu yakıtların en başında gelmektedir. Petrol, yakıt olarak kullanımının yanı sıra sanayi sektöründe kullanılan başlıca hammaddelerden biridir. Bu sebeple petrol fiyatlarında meydana gelen değişmeler hem işletmeleri hem de yatırımcıların kararlarını etkilemektedir.

Finans alanında hisse senetlerinin fiyatlarını etkileyen unsurlar en fazla araştırılan konulardan birisidir. Petrol, yakıt olarak kullanımının yanı sıra sanayi sektöründe kullanılan başlıca hammaddelerden biridir. Bu sebeple petrol fiyatlarında meydana gelen değişmeler hem işletmeleri hem de yatırımcıların kararlarını etkilemektedir. Ardından Toda-Yamamoto testi ile değişkenler arasında herhangi bir nedensellik ilişkisinin var olup olmadığ 1 , nedensellik ilişkisi varsa bu ilişkinin yönü araştırılmıştır.

Araştırmada kullanılan Lee-Strazicich birim kök testlerinin sonuçlarına göre ham petrol ve katılım endeksleri değişkenlerinin düzey değerlerinin durağan olmadığ durağan hale geldikleri tespit edilmiştir. Toda-Yamamoto nedensellik testi sonuçlarına göre ise ele alınan dönemlerde ham petrol fiyatları serisinden, Katılım -30 endeksi ve Katılım -Model Portföy endeksine doğru bir nedensellik ilişkisine rastlanmamıştır. Diğer taraftan ham petrol fiyatlarından Katılım -50 endeksine doğru ise bir nedensellik ilişkisine rastlanmıştır. Benzer şekilde katılım endekslerinden de ham petrol fiyatlarına doğru bir nedensellik ilişkisi tespit edilememiştir.

Sonuç olarak araştırmanın gerçekleştirildiği dönemlerde ham petrol fiyatlarının, Katılım -30 endeksini ve Katılım -Model Portföy endeksini etkilemediği, ancak ham petrol fiyatlarının, Katılım -50 endeksini etkilediği görülmüsşür. Dolayısıyla yatırımcıların, Katılım -50 endeksinde bulunan şirketlerin hisse senetlerine yatırım yaparken petrol fiyatlarındaki değişiklikleri yakından takip etmeleri önem arz etmektedir.

Ayrıca diğer endekslere göre sadece Katılım -50 endeksi ile petrol fiyatları arasında ilişki çıkmasının sebebi ilgili endekste şirket çeşitliliğinin ve enerji kullanımının daha fazla olması olabilir. Öte yandan petrol zengini Müslüman Arap ülkeleri petrol fiyatlarındaki değişimlerden doğrudan etkilenmektedir. Petrol fiyatlarındaki olası artış bu ülkelerin gelirlerini artıracak, gelirleri artan ülkeler dolaylı sermaye yatırımlarını dini hassasiyetlerini gözeterek katılım endekslerindeki şirketlere yapabileceklerdir. Çalışma sonuçları Hvang vd. (1996), Cong vd. (2008), İşcan (2010), Syzdykova Oralbaykızı (2019), Konuşkan ve Kocabıyık (2019) ile benzerlik göstermektedir. Çalışmaya katılım endekslerini etkileyebilecek farklı makro ekonomik değişkenler eklenerek çalışma daha ileri götürülebilir. 


\section{KAYNAKÇA}

Abdioğlu, Z., ve Değirmenci, N. (2014) “Petrol Fiyatları-Hisse Senedi Fiyatları İlişkisi: BİST Sektörel Analiz”, Kafkas Üniversitesi İktisadi ve İdari Bilimler Fakültesi Dergisi, 5(8), 1-24.

Adaramola, A. O. (2012) "Oil Price Shocks and Stock Market Behaviour: The Nigerian Experience", Journal of Economics, 3(1), 19-24.

Al-Fayoumi, N.A. (2009) "Oil Prices and Stock Market Returns in Oil Importing Countries: The Case of Turkey, Tunisia and Jordan”, European Journal of Economics, Finance and Administrative Sciences, 16, 84-98.

Alsu, E. (2019) "Petrol Fiyatları ve Borsa Endeks Değeri Arasındaki İlişki: Ortadoğu Ülkeleri Örneği”, OPUS Uluslararası Toplum Araştırmaları Dergisi, 1(1).

Arouri, M.E.H. ve Rault, C. (2009) "Oil Prices and Stock Markets: What Drives What in The Gulf Corporation Council Countries?", William Davidson Institute Working Paper, 1-19.

Basher, S. A. ve Sadorsky, P. (2006) “Oil Price Risk and Emerging Stock Markets”, Global Finance Journal, 17(2), 224251.

BP (2019) "BP Statistical Review of World Energy 68th Edition”, Https://Www.Bp.Com/Content/ Dam/Bp/BusinessSites/En/Global/Corporate/Pdfs/Energy-Economics/Statistical-Review/Bp-Stats-Review-2020-Full-Report.Pdf, Erişim Tarihi 01.11.2019.

BP (2020) "BP Statistical Review of World Energy 69th Edition", Https:/Www.Bp.Com/Content/ Dam/Bp/Business-Sites/En/Global/Corporate/Pdfs/Energy-Economics/Statistical-Review/Bp-Stats-

Revie W-2019-Full-Report.Pdf, Erişim Tarihi 01.08.2020.

Chiou, J. ve Lee, Y.H. (2009) “Jump Dynamics and Volatility: Oil and The Stock Markets”, Energy Journal, 34, 788796.

Chittedi, R.K. (2012) “Do Oil Prices Matters For Indian Stock Markets? an Empirical Analysis”, Journal of Applied Economics and Business Research, 2(1), 2-10.

Cong, R.G., Wei, Y.M., Jiao, J.L. ve Fan, Y. (2008) "Relationships Between Oil Price Shocks and Stock Market: an Empirical Analysis From China", Energy Policy, 3544-3553.

Doğan, B. (2017) "Ekonomik Küreselleşme ve Büyüme İlişkisi: Türkiye Örneği Toda-Yamamoto Nedensellik Analizi”. Finans Politik \& Ekonomik Yorumlar, 54(628), 19-27.

El-Sharif I., Brown, D., Burton, B. Nixon B. ve Russell, A. (2005) "Evidence on The Nature and Extent of The Relationship Between Oil Prices and Equity Values in The UK”, Energy Economics, 819-830.

Esenyel, N. (2017) “Türkiye’de Enerji Yakınsama Hipotezinin Sınanması: Yapısal Kırılmalı Birim Kök Analizi” Sosyal Bilimler Araştırma Dergisi, 6(3), 42-52.

Faff, W.R. ve Brailsford, T.J. (1999) “Oil Price Risk and The Australian Stock Market”, Journal of Energy Finance and Development, 4(1), 69-87.

Gay, R. D. Jr. (2008) "Effect of Macroeconomic Variables on Stock Market Returns For Four Emerging Economies: Brazil, Russia, India and China", International Business and Economics Research Journal, 7 (3), 1-8.

Güler, S., Tunç R. ve Orçun, Ç. (2010) "Petrol Fiyat Riski ve Hisse Senedi Fiyatları Arasındaki İlişkinin Belirlenmesi: Türkiye'de Enerji Sektörü Üzerinde Bir Uygulama”, Atatürk Üniversitesi İktisadi ve İdari Bilimler Dergisi, 24(4), 297-315.

Gündoğan, H. ve Dilek, T. O. K. (2019) "Petrole Bağımlı Ülkelerde Petrol Fiyatlarının Sanayi Üretimine Etkisi: Panel Nedensellik Çalışması”, Ege Akademik Bakış Dergisi, 19(1), 131-140.

Hacıhasanoğlu, E. ve Soytaş, U. (2011) “Emtia Fiyatları ile Hisse Senedi Piyasaları Arasındaki İlişki” İşletme Fakültesi Dergisi, 12(1), 53-65.

Hammoudeh, S. ve Elesia, E. (2004) "Dynamic Relationships Among GCC Stock Markets and NYMEX Oil Futures," Contemporary Economic Policy, 22 (2), 250-269.

Huang, R.D., Masulis, R.W. ve Stoll, H.R. (1996) "Energy Shocks and Financial Markets," The Journal of Future Markets, 1-25.

İşcan, E. (2010) "Petrol Fiyatının Hisse Senedi Piyasası Üzerindeki Etkisi”, Maliye Dergisi, 158, 607-617.

Jones, C.M. ve Kaul, F. (1996) "Oil and The Stock Markets” The Journal of Finance, 51(2), 463-491.

Kaneko, T. ve Lee, B-S. (1995) "Relative Importance of Economic Factors in The U.S. and Japanese Stock Markets", Journal of The Japanese and International Economies, 9(3), 290-307.

Kapusuzoğlu, A. (2011) "Relationships Between Oil Price and Stock Market: An Empirical Analysis From İstanbul Stock Exchange (ISE)", International Journal of Economics and Finance, 3(6), 99-106.

Karcıoğlu, R., Özcan M. ve Ağırman, E. (2017) "Petrol Fiyatları ve BIST Sektör Endeksleri İlişkisi” International Conference On Eurasian Economies 2017.

Kendirli, S. ve Çankaya, M. (2016) “Ham Petrol Fiyatlarının Bist 100 ve Bist Ulaştırma Endeksleri ile İlişkisi” Kastamonu Üniversitesi İktisadi ve İdari Bilimler Fakültesi Dergisi, 12, 136-14.

Kırıcı Altınkeski, B. ve Çevik, E. İ. (2019) "Petrol Fiyat Şoklarının Hisse Senedi Piyasası Üzerine Etkisi: Türkiye Örneği” Iğdır Üniversitesi Sosyal Bilimler Dergisi, 165-179.

Konuşkan, A. ve Kocabıyık, T. (2019) “Altın, Petrol, Döviz ve Borsa Endeksi Arasındaki İlişkinin Nedensellik Analizi ile Keşfi: Türkiye Örneği”, Uluslararası İşletme, Ekonomi ve Yönetim Perspektifleri Dergisi, 3(1), 1-19. 
KPMG, (2019) “Sektörel Bakış- Enerji - 2019”. Https://Assets.Kpmg/Content/Dam/Kpmg/Tr/Pdf/2019/03/ SektorelBakis-2019-Enerji.Pdf. Erişim Tarihi 01.11.2019.

Le, T.H. ve Chang, Y. (2011) "The Impact of Oil Price Fluctuations on Stock Markets in Developed and Emerging Economies", Economic Growth Centre Working Paper Series, 1-36.

Lee, J. ve Strazicich, M. C. (2003) "Minimum Lagrange Multiplier Unit Root Test With Two Structural Breaks" Review of Economics and Statistics, 85(4), 1082-1089.

Maghyereh, A. (2004) “Oil Price Shocks and Emerging Stock Markets: A Generalized VAR Approach”, International Journal Of Applied Econometrics and Quantitative Studies, 1(2), 27-40.

Maghyereh, A. Ve Al-Kandari, A. (2007) "Oil prices and stock markets in GCC Countries: New Evidence from nonlinear cointegration Analysis", Managerial Finance, 33(07), 449-460.

Narayan, P.K. ve Narayan, S. (2009) “Modelling The Impact of Oil Prices on Vietnam's Stock Prices”, Applied Energy, 87(1), 356-361.

Odusami, B.O. (2009) “Crude Oil Shocks and Stock Market Returns”, Applied Financial Economics, 19(4), 291 -303.

Öget, E. ve Şahin, S. (2017) "Hisse Senetleri ile Altın Ons Fiyatları ve Ham Petrol Fiyatları Arasındaki Eşbütünleşme İlişkisi: BİST 100” Ulak Bilge, 5(11), 637-653.

Öner Badurlar, İ. (2011) “Türkiye’de Döviz Kuru Beklentilerinin ve Ülkenin Risk Primindeki Dalgalanmaların Nominal Döviz Kuru Oynaklığı Üzerindeki Etkisi” Paper Presented at Econanadolu 2011: Anadolu International Conference İn Economics II, 1-20.

Özmerdivanlı, A. (2014) "Petrol Fiyatları ile BIST 100 Endeksi Kapanış Fiyatları Arasındaki İlişki”, Akademik Bakış Uluslararası Hakemli Sosyal Bilimler Dergisi, (43).

Park, J. ve Ratti, R.A. (2008) “Oil Price Shocks And Stock Markets in The U.S. and 13 European Countries”, Energy Economics, 30(5), 2587-2608.

Roselee S. S., Samad, F. ve Sonal B. (2009) "Performance and Volatility of Oil and Gas Stocks: A Comparative Study On Selected O\&G Companies", International Business Research, 2(4), 87-99.

Sadorsky, P. (1999) "Oil Price Shocks and Stock Market Activity”, Energy Economics, 21(5), 449-469.

Sivri, U. (2010) "Şokların Yabancı Ziyaretçi Sayısı ve Yabancı Ziyaretçi Harcamaları Üzerindeki Etkisi Kalıcı Mıdır?" TISK Akademi, 5(10), 220-237.

Syzdykova Oralbaykızı, A. (2019) "Petrol Fiyat Değişimlerinin BİST Endeks Getirileri Üzerindeki Etkisinin Analizi”, Bilecik Şeyh Edebali Üniversitesi Sosyal Bilimler Enstitüsü Dergisi, 247-265.

Şener, S., Yılancı, V. ve Tıraşoğlu, M. (2013) "Petrol Fiyatları ile Borsa İstanbul'un Kapanış Fiyatları Arasındaki Saklı İlişkinin Analizi”, Selçuk Üniversitesi İktisadi ve İdari Bilimler Fakültesi Sosyal ve Ekonomik Araştırmalar Dergisi, 62, 231-248.

T.C Enerji ve Tabii Kaynaklar Bakanlığı (2020) “Bilgi Merkezi” Https://Enerji.Gov.Tr/Bilgi-Merkezi-Enerji-Petrol, Erişim Tarihi: 01.08.2020.

Toda, H. Y. ve Yamamoto, T. (1995) "Statistical Inference in Vector Auto Regressions with Possibly İntegrated Processes" Journal of Econometrics, 66, 225-250.

Ünlü, U. ve Topçu, M. (2012) "Do Oil Prices Directly Affect Stock Markets: Evidence From Istanbul Stock Exchange”, İktisat, İşletme ve Finans, 27(319), 75-88.

Yıldırım, E. ve İşcanoğlu Çekiç, A. (2019) “Altın, Ham Petrol, GVZ ve OVX'in Türk Finansal Piyasalarına Simetrik ve Asimetrik Etkileri”. Uluslararası Yönetim İktisat ve İşletme Dergisi, 15(3), 714-731.

Yıldırım, M., Bayar, Y. ve Kaya, A. (2014) “Enerji Fiyatlarının Sanayi Sektörü Hisse Senedi Fiyatları Üzerindeki Etkisi: BİST Sanayi Sektörü Şirketleri” Muhasebe ve Finansman Dergisi, (62), 93-108. 